\title{
Replication-restricted vaccinia as a cytokine gene therapy vector in cancer: Persistent transgene expression despite antibody generation
}

\author{
Sutapa Mukherjee, ${ }^{1}$ Thomas Haenel, ${ }^{1}$ Robyn Himbeck, ${ }^{1}$ Bernadette Scott, ${ }^{1}$ Ian Ramshaw, ${ }^{2}$ \\ Richard A. Lake, ${ }^{1}$ Gerry Harnett, ${ }^{3}$ Peter Phillips, ${ }^{3}$ Sue Morey, ${ }^{4}$ David Smith, ${ }^{3}$ \\ J. Andrew Davidson, ${ }^{1}$ Arthur W. Musk, ${ }^{4}$ and Bruce Robinson ${ }^{1}$ \\ ${ }^{1}$ Department of Medicine, University of Western Australia, Queen Elizabeth II Medical Center, Nedlands, \\ Australia; ${ }^{2}$ Viral Engineering Group, Division of Cell Biology, John Curtin School of Medical Research, \\ Australian National University, Canberra, Australia; ${ }^{3}$ Division of Microbiology, The Western Australian \\ Center for Pathology and Medical Research, Nedlands, Australia; and ${ }^{4}$ Department of Respiratory Medicine, \\ Sir Charles Gairdner Hospital, Nedlands, Australia.
}

\begin{abstract}
Background: As antitumoral immunity requires the generation of local immunity directed against tissue proteins, we attempted to recreate within tumors the same environment found within tissues affected by autoimmune diseases (i.e., prolonged cytokine expression). Vaccinia virus (VV) has not been widely used as a cytokine gene therapy vector because of presumed high immunogenicity that would likely make repeated injections impossible; therefore, we modified it by inserting the cytokine gene into the thymidine kinase region, rendering it replication-restricted. The cytokine chosen was human interleukin-2 (IL-2), a molecule with powerful antitumoral effects.

Methods: Six patients with the treatment-resistant tumor malignant mesothelioma received intratumoral (i.t.) VV-IL-2 therapy for 12 weeks by injection of $10^{7}$ plaque-forming units of VV-IL-2 per dose. Serial tumor biopsies, sputum, urine, and blood samples were tested for VV-IL-2 mRNA expression; VV culture and T-cell infiltrates were evaluated by immunohistochemistry. Patients and contacts of patients were monitored for changes in VV immunoglobulin G (IgG) levels and clinical evidence of VV infection.

Results: VV-IL-2 was not excreted and was only cultured in one patient from tumor biopsies. A T-cell infiltrate was detected in $50 \%$ of tumor biopsies. VV-IL-2 mRNA expression was highest on days 1-3 postinjection and was detected for up to 3 weeks after each injection even though VV IgG levels rose in all patients. No significant toxicities, infection of patient contacts, or tumor regressions were observed.

Conclusions: I.t. VV-IL-2 administration is safe, is associated with minimal toxicity, and results in i.t. expression of VV-IL-2 for up to 3 weeks postinjection regardless of the level of anti- $\mathrm{V} V \lg \mathrm{G}$ titers generated. This suggests that $\mathrm{V} V$ may be a good vector for repeated cytokine gene therapy of solid human cancer. Cancer Gene Therapy (2000) 7, 663-670
\end{abstract}

Key words: Gene therapy; vaccinia virus; interleukin-2; malignant mesothelioma.

$\mathrm{M}$ ost of the identified human tumor T-cell antigens (Ags) are self Ags, ${ }^{1}$ and it is believed that the type of immune response required to destroy an established tumor parallels that which is found in destructive, autoimmune diseases. This is encouraging, as autoimmune processes can effectively destroy human tissue, implying that if we can recreate the same conditions in cancer tissue, a prolonged immune attack may occur. Two conditions must be met for tumors to undergo immune-

Received December 28, 1998; accepted July 25, 1999.

Address correspondence and reprint requests to Prof. Bruce Robinson, University Department of Medicine, 4th Floor, G Block, QEII Medical Center, Nedlands, Western Australia 6009. E-mail address: bwsrobin@cyllene.uwa.edu.au mediated destruction. First, immunological events must occur within the tumor (i.e., the tumor must become infiltrated with activated T lymphocytes producing cytokines that augment host antitumoral activities). ${ }^{2}$ Second, this process must occur over a relatively prolonged period of time. ${ }^{3}$

To generate high concentrations of cytokines within a tumor environment over prolonged periods, two main therapeutic options exist. First, cytokines can be constantly infused into tumor tissue. ${ }^{4}$ This process is limited by the technical difficulties of inserting and maintaining intratumoral (i.t.) catheters, by problems related to recombinant cytokine distribution within the tumor, and by unexpected side effects. Second, cytokines can be induced in the tumor by cytokine gene transfer (i.e., by injecting the relevant cytokine gene in such a way that 
the tumor cells themselves produce cytokines). ${ }^{5}$ This approach has the theoretical attraction of inducing the prolonged expression of high concentrations of cytokine within the tumor milieu for prolonged periods after each injection.

Most clinical trials of human cancer gene therapy have used retrovirus or adenovirus as vectors. ${ }^{5-7}$ Vaccinia virus (VV) has not been used previously as a vector for cytokines in patients with malignancy. This is largely related to the presumed theoretical disadvantage of its inherent immunogenicity and the likely induction of high levels of anti-VV antibodies (Abs), which might be expected to limit the effectiveness of repeated doses of VV-cytokine constructs. We chose to use VV in this study because its virology and safety have been welldescribed, having been used in millions of individuals worldwide in the control of smallpox. We also reasoned that insertion of the interleukin-2 (IL-2) gene into the thymidine kinase (TK) region of the VV would render it replication-restricted. This might allow more prolonged expression within tumor cells, where TK is produced at higher levels than in normal tissues. Substantial animal data exist supporting the notion that VV-cytokine constructs can have profound effects on host immune responsiveness. ${ }^{8-11}$

We chose to study VV-IL-2 in malignant mesothelioma (MM), an aggressive tumor that arises from serosal surfaces such as pleura and peritoneum. ${ }^{12} \mathrm{MM}$ is increasing in incidence throughout the world, largely due to widespread exposure to asbestos; it is uniformly fatal and is resistant to all standard forms of therapy. ${ }^{13}$ There is an accumulating body of data that supports the concept that MM may be susceptible to immunotherapeutic approaches. ${ }^{14,15}$ The majority of these data are based on the murine model of MM, which almost exactly mimics its human counterpart in terms of pathology, biology, immunology, and clinical behavior. ${ }^{16}$ There are also limited data from humans with MM supporting the concept that under some circumstances this disease may be susceptible to immunological approaches, such as the relationship between tumor-infiltrating lymphocyte proportions and prognosis, ${ }^{17}$ partial responsiveness to the systemic immunomodulatory agent interferon- $\alpha,{ }^{18}$ rare transient spontaneous regressions associated with lymphocytic infiltration (our unpublished observations), and our recently demonstrated association between MM regression and mononuclear cell infiltration in patients undergoing continuous intralesional infusion of recombinant granulocyte-macrophage colony-stimulating factor. ${ }^{4}$

IL-2 had powerful anti-MM effects in our animal studies using cytokine gene transfer approaches in $\mathrm{MM} ;{ }^{19}$ on that basis, this cytokine was chosen for our initial human clinical study.

The pilot study reported here was established to determine the safety of the vector, particularly in terms of toxicity for the patient and possible transmission to contacts, the level and duration of gene expression after vector injection into the tumor, the biological effects induced by this approach within the tumor, and antitumoral activity. The results demonstrate that VV-IL-2, when administered i.t. to a maximum dose of $10^{7}$ plaque-forming units (PFU) per patient per week, is without significant toxicity, is not transmitted, and, importantly, induces VV-IL-2 mRNA expression for up to 3 weeks after each injection, regardless of the level of systemic anti-VV immunity, inducing modest biological effects within the region of injection.

\section{MATERIALS AND METHODS}

\section{Patients}

Eligible patients were those with confirmed histological or cytological diagnosis of MM, measurable disease in the form of a subcutaneous (s.c.) nodule protruding through the chest wall, life expectancy of $\geq 12$ weeks at enrollment, symptoms attributable to MM, and normal hematological and biochemical parameters.

\section{Protocol}

Written informed consent was obtained from each patient before commencement of the study. The study was approved by the Human Rights Committee of the University of Western Australia, the Clinical Drug Trial Committee of Sir Charles Gairdner Hospital, and the Gene Therapy Committee of the National Health and Medical Research Council of Australia.

All staff involved in the study and close contacts of the patients received vaccinia vaccination, supplied by Commonwealth Serum Laboratories (Melbourne, Australia). The vaccine was delivered intradermally to the deltoid region by a standard multiple pressure technique using a 21-gauge needle. All individuals showed evidence of vaccine replication at the inoculation site.

Six patients were enrolled. Injection of VV-IL-2 was performed by insertion of a 21-gauge needle $\sim 5 \mathrm{~cm}$ into the center of the s.c. nodule. A single needle track was made, and the injection of $1 \mathrm{~mL}$ volume was performed in a volume of $\sim 5$ $\mathrm{mL}$ of tumor by maneuvering the needle slightly within the tumor to increase the volume of tumor exposed to the virus. Because of an early theoretical risk of disseminated VV infection, patient 1 received a pretreatment VV revaccination. This patient then had an initial dose of VV-IL-2 of $10^{5} \mathrm{PFU}$, with dose escalation over the next two cycles to $10^{7}$ PFU. Because of low VV-IL-2 yields from the injection site of this first patient, the remaining patients did not receive VV vaccination before commencement of therapy.

Patients 1 through 4 had three weekly VV-IL-2 injections. As polymerase chain reaction (PCR) analysis of VV-IL-2 expression showed that transgene expression fell after 1 week, patients 5 and 6 received weekly i.t. injections of $10^{7} \mathrm{PFU}$. In patients 1 and 2, tumor biopsies and other specimens, as listed below, were obtained before each treatment and subsequently on days 3 and 8 of each cycle. Tumor biopsies and other specimens, as listed below, were obtained from patients 3 and 4 before each treatment and on days 1 and 7 of each cycle. In patients 5 and 6 , tumor biopsies and other samples were obtained before each treatment and on day 1 of each cycle. At least three tumor biopsies were taken in all patients from the same area of tumor tissue that had been injected with VV-IL-2 using a 14-gauge Tru-cut biopsy needle (Baxter, Deerfield, Ill) on sampling days as listed above. Chest $\mathrm{x}$-rays and computed tomography (CT) scans were performed immediately before the beginning of treatment and at the conclusion of the treatment in each patient. In addition, chest radiographs were performed at three to four weekly intervals during the study. 
Direct measurement of the s.c. nodule of MM being injected was performed weekly.

\section{Preparation of $V$ V-IL-2}

A recombinant $\mathrm{VV}$ expressing the human IL-2 gene was constructed by isolating a $1-\mathrm{kb}$ XhoI from pcD-IL-2 (K. I. Arai, DNAX Research Institute, Palo Alto, Calif). A 500-bp human IL-2 cDNA was removed using an $R s a$ I restriction enzyme and was inserted into plasmid $\mathrm{pBCB} 07$. This plasmid was introduced into the TK gene in the $\mathrm{J}$ region of the $\mathrm{NYCBOH}$ strain of $\mathrm{VV}$. TK-negative recombinant viruses were then selected for IL-2 expression. (A 143B fibroblast cell line was used to produce the initial VV-IL-2.) The recombinant virus expressing IL-2 was plaque-purified and grown in fibroblasts harvested from specific pathogen-free chicken embryos, under conditions appropriate to the Therapeutic Goods Act. The recombinant virus vaccine has been reviewed by the Therapeutic Goods Administration Laboratories.

To test the production of IL- 2 in vitro, $10^{6}$ cells of two human mesothelioma cell lines (JU77 and NO36) were cultured and infected with VV-IL-2 at a multiplicity of infection (MOI) of 0.5 for 24 and 72 hours, respectively; the was supernatant collected and assayed for IL-2 by enzyme-linked immunosorbent assay (Genzyme, Cambridge, Mass).

\section{Evaluation of toxicity}

Toxicity was assessed by the development of fever, malaise, nausea, vomiting, persistent tumor pain (not attributable to pain of biopsy), injection site pain, dyspnea, skin pustules, rashes, cough, sputum, diarrhea, change in Eastern Cooperative Oncology Group (ECOG) performance status, hematology, or biochemistry that could not be attributed to another cause and was temporally related to the administration of VV-IL-2.

\section{Evaluation of viral transmission}

Tumor biopsies, urine, blood, mouth wash samples, sputum, and pleural fluid (where available) were obtained and sent for viral culture. Sera from patients and their close contacts were obtained and tested for the presence of anti-VV immunoglobulin $\mathrm{G}(\mathrm{IgG})$ by an indirect immunofluorescent $\mathrm{Ab}$ assay.

Viral culture was performed using Vero cell cultures in 48-well trays. Specimens (100 $\mu \mathrm{L})$ were inoculated, and plates were centrifuged at $2000 \times g$ for 1 hour at $37^{\circ} \mathrm{C}$ to enhance infectivity. This method had been tested to show its ability to support the growth of VV and VV-IL-2.

\section{Vaccinia Ab assay}

RK-13 cell monolayers in 96-well flat-bottom plates were infected with a dose of VV that was sufficient to produce discrete foci of infection. Serial 2-fold dilutions of the patient's sera were added, and $\mathrm{Ab}$ binding was detected using antihuman IgG fluorescein isothiocyanate conjugate (Silenus, Victoria, Australia) and ultraviolet microscopy.

\section{Gene expression}

Reverse transcriptase (RT) VV-IL-2 PCR was performed using VV-IL-2 sequence primers on tumor biopsies. Tumor biopsies were homogenized in the presence of RNAzol B (Tel-Test, Friendswood, Tex) using a polytron blender. Total RNA was extracted according to the RNAzol B protocol. Up to $5 \mu \mathrm{g}$ of total RNA was reverse transcribed in the presence of ribonuclease inhibitor $(40 \mathrm{U})$ using oligo $(\mathrm{dT})_{15-18}(500 \mathrm{ng})$ and $12.5 \mathrm{U}$ of avian Moloney virus RT (Promega, Madison, Wis) at $42^{\circ} \mathrm{C}$ for 1 hour. PCR was performed on a thermocycler (Perkin-Elmer, Norwalk, Conn) using oligonucleotide primers specific for human IL-2 (5'-ATG TAC AGG ATG CAA CTC CTG TCT T-3') and $3^{\prime}$ of the EcoRI site in the VV-TK gene (5'-GTC CCA TCG AGT GCG GC-3'). The reaction mixture contained $10 \mathrm{pmol}$ of each primer, $1.6 \mathrm{mM}$ deoxynucleoside triphosphates, $2.0 \mathrm{mM} \mathrm{Mg}^{2+}$, and $0.2 \mathrm{U}$ of Taq polymerase (Promega). The PCR consisted of 1 cycle of denaturation at $94^{\circ} \mathrm{C}$ (4 minutes), annealing at $55^{\circ} \mathrm{C}(1$ minute), and extension at $72^{\circ} \mathrm{C}(2$ minutes $)$. This was followed by 49 cycles of denaturation at $94^{\circ} \mathrm{C}$ (30 seconds), annealing at $55^{\circ} \mathrm{C}$ ( 1 minute), and extension at $72^{\circ} \mathrm{C}$ ( 2 minutes). PCR products were visualized by ethidium bromide staining after electrophoresis through $1.2 \%$ (wt/vol) agarose. A glyceraldehyde-3-phosphate dehydrogenase internal control was amplified from all cDNA samples using specific primers (sense, 5'-GAA GGT CGG TGT GAA CGG ATT-3'; antisense, 5'-CGG AAG GGG CGG AGA TGA TGA-3'). The negative control RNA from activated human blood $\mathrm{T}$ lymphocytes was tested using these primers before testing patient tumor biopsy samples and during the study; this RNA remained negative.

\section{Tumor biopsy immunohistochemical staining}

Frozen sections of tumor biopsies were obtained, fixed in $1 \%$ paraformaldehyde, and washed; endogenous peroxidase was blocked by $1 \%$ hydrogen peroxide. Primary Abs CD3, CD4, and CD8 (Dako, Carpinteria, Calif) were then applied, followed by the secondary Ab, biotinylated sheep anti-mouse Ig (Jackson Laboratories, West Grove, Penn), and the addition of streptavidin-horseradish peroxidase (Dako). Staining was visualized by precipitating 3,3 diaminobenzidine (Sigma, St. Louis, Mo) and counterstaining with hematoxylin.

\section{RESULTS}

In vitro production of IL-2

The two human MM cell lines (JU77 and NO36) infected with VV-IL-2 produced significant amounts of IL-2 at an MOI of 0.5, ranging from 1192 to $3767 \mathrm{ng} / \mathrm{mL}$ at 24 hours (Fig 1) These data are consistent with the known kinetics of VV-IL-2 infection of cells, with maximal production of IL-2 usually seen at 24 hours postinfection. ${ }^{8}$

\section{Patient characteristics}

Six patients were administered VV-IL-2 i.t., and their characteristics are summarized in Table 1. In brief, patients were between 55 and 71 years of age; five were male and one was female; all had an ECOG performance status of 1 and a mean of 16 months from MM diagnosis (range 8-27 months). Patients had between 2 and 12 treatments (mean 5 treatments).

\section{Toxicity}

No toxicity was observed. There was no change in hematological or biochemical parameters in any patient during the course of treatment. 
Figure 1. In vitro production of IL-2 from two human mesothelioma cell lines (JU77 and NO36) after infection with VV-IL-2 at an $\mathrm{MOI}$ of 0.5 at 24 and 72 hours. After 72 hours, all cells were infected; a later timepoint would not have provided accurate data at this MOI.

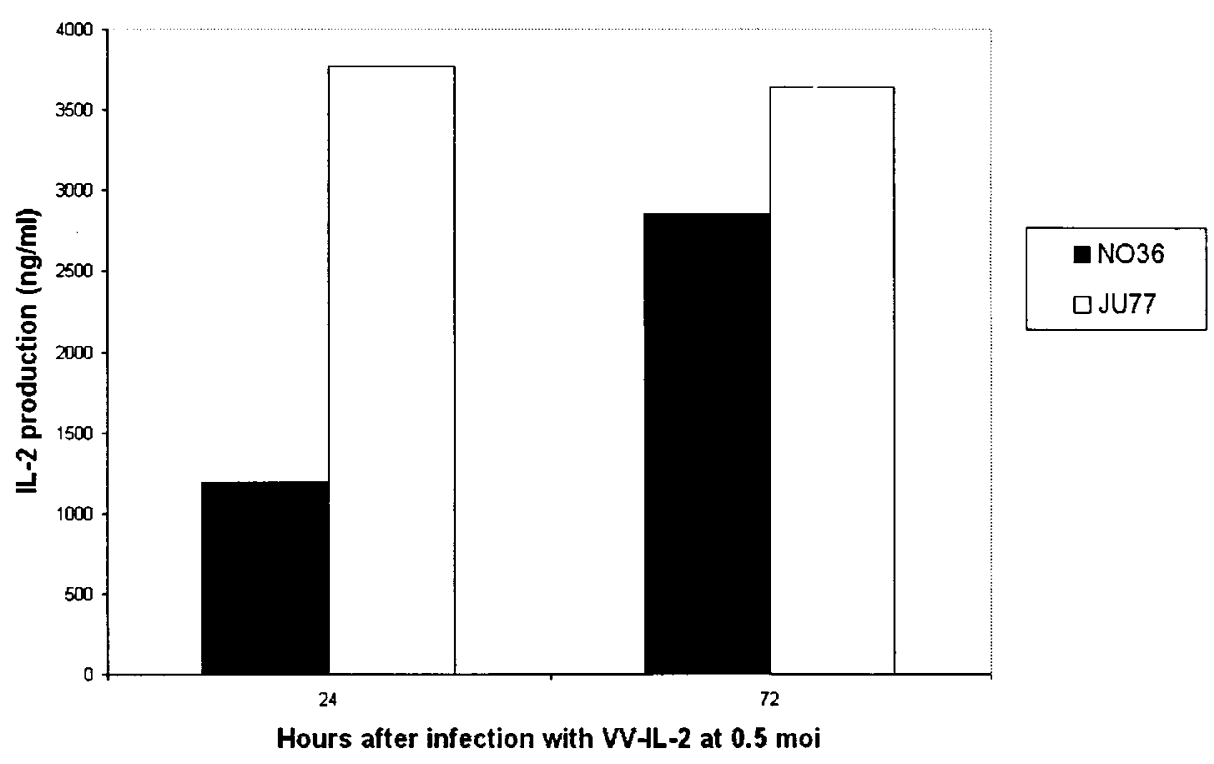

\section{Transmission}

VV-IL-2 excretion. VV-IL-2 was not cultured from sputum, urine, mouth wash samples, pleural fluid (obtained only for patient 6 ), or blood in any patient. The tumor biopsies from patient 4 were positive on culture for $\mathrm{VV}$ on all three samples taken during the second cycle of treatment. All other patients' tumor biopsies were negative for VV on culture.

Clinical features and Ab titers of contacts. A total of 31 contacts of the 6 patients were evaluated. None of these contacts developed any signs or symptoms of VV infection at any stage after exposure to a patient. None of the unvaccinated contacts showed any increase in serological titer to VV after exposure to a patient receiving i.t. VV-IL-2.

\section{Immune response to $V V$ in patients}

VV IgG titers increased progressively with treatment in all patients, from a minimum titer of $1 / 10$ to a maximum titer of 1/1280, indicating viral protein production in vivo (Fig 2). The exception was patient 1 , who had high titers before treatment due to revaccination with VV.

Table 1. Patient Characteristics

\begin{tabular}{cccccc}
\hline $\begin{array}{c}\text { Patient } \\
\text { number }\end{array}$ & $\begin{array}{c}\text { Age } \\
\text { (years) }\end{array}$ & Sex & $\begin{array}{c}\text { Performance } \\
\text { status } \\
\text { (ECOG) }\end{array}$ & $\begin{array}{c}\text { Months } \\
\text { since } \\
\text { diagnosis }\end{array}$ & $\begin{array}{c}\text { Number of } \\
\text { treatments } \\
\text { administered }\end{array}$ \\
\hline 1 & 57 & Male & 1 & 8 & 4 \\
2 & 66 & Male & 1 & 17 & 4 \\
3 & 55 & Female & 1 & 27 & 3 \\
4 & 65 & Male & 1 & 16 & 2 \\
5 & 61 & Male & 1 & 19 & 7 \\
6 & 71 & Male & 1 & 9 & 12 \\
\hline
\end{tabular}

Viral gene expression

VV-IL-2 mRNA was detected by RT-PCR (50 cycles) in tumor biopsies for up to 3 weeks after VV-IL-2 injection, as shown in Figure 3. This shows that in patients 1 through 4, the percentage of total positive VV-IL-2 mRNA tumor biopsies was greatest on days 1-3 (67\% positive) after VV-IL-2 injection; this percentage subsequently decreased by days $5-8$ (54\% positive) and day 21 just before the next injection (40\% positive). Contingency table analysis indicated no statistically significant difference between the three timepoints $(P=.46)$. Similarly in patients 5 and $6,63 \%$ of tumor biopsies were positive for VV-IL-2 mRNA on day 1 after VV-IL-2 injection. Figure 4 illustrates that VV-IL-2 mRNA was detectable in tumor biopsies regardless of anti-VV IgG titer. Contingency table analysis indicated that there was no statistically significant difference between the two groups $(P=.41)$. This suggests that the presence of high levels of anti-VV Abs does not influence the pattern of expression of VV-IL-2 mRNA in tumor tissue.

\section{$T$ lymphocytes within tumor biopsies}

A total of 36 tumor biopsies were available for immunohistochemistry staining at different timepoints postinjection. Of these, 18 showed staining with CD3, a nonspecific T-cell marker, when compared with pretreatment controls. Satisfactory staining with CD4 and CD8 could not be obtained due to limited section material.

\section{Clinical responses}

No significant tumor regression was observed either radiologically or clinically. 


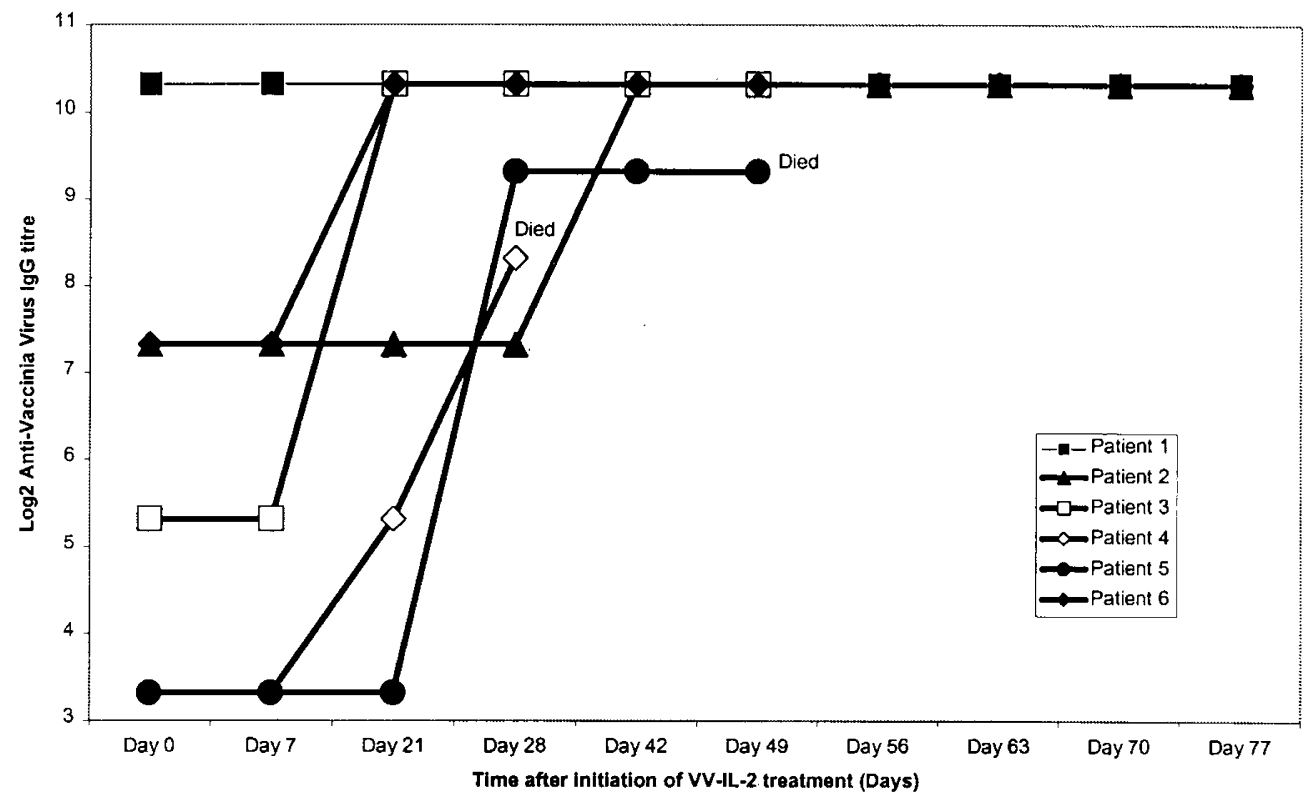

Figure 2. Anti-VV IgG titers in six patients receiving VV-IL-2 therapy. In all patients, IgG titers were measured at baseline (day 0 ) and just before each VV-IL-2 injection. In addition, IgG titers were measured on days 3 and 8 of each treatment cycle in patients 1 and 2 , on days 1 and 7 of each treatment cycle in patients 3 and 4 , and on day 1 of each treatment cycle in patients 5 and 6 .

\section{DISCUSSION}

This is the first study using vaccinia-cytokine constructs in patients with solid malignancy; it has resulted in the surprising finding that the use of $\mathrm{VV}$ as a vector is associated with relatively prolonged viral gene expression within tumors after repeated injections despite the presence of systemic humoral immunity.

MM is an untreatable tumor that is considered to be an ideal target disease for gene therapy approaches, particularly when seen in the context of a progressive increase in the incidence of this tumor worldwide. ${ }^{18,19}$ Evidence that MM may be susceptible to immunotherapeutic approaches has come from a number of laboratories worldwide, and we have good evidence that the production of cytokines within MM deposits induces strong anti-MM immunity. We selected the IL-2 gene for our initial experiments because it had powerful effects in our animal model ${ }^{19}$ and its effects in human cancer clinical trials have been well-described.,20-24

Our initial task was to evaluate the toxicity of this VV-cytokine construct. Although unmodified VV has

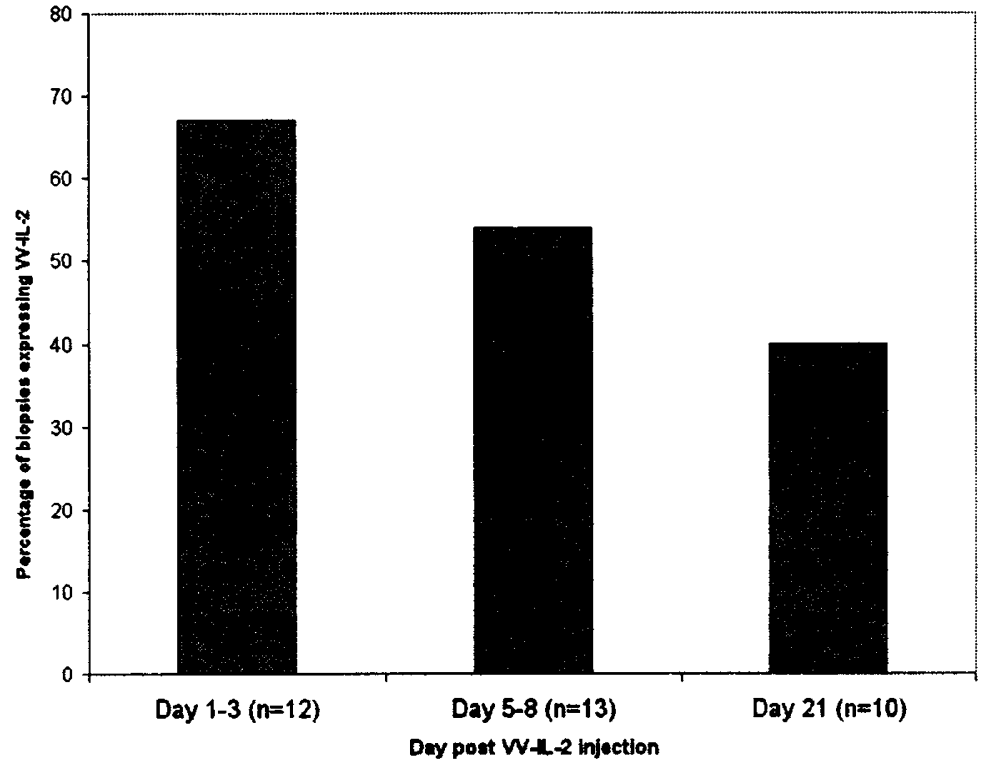

Figure 3. Percentage of tumor biopsies expressing VVIL-2 in patients 1 through 4 . Measurements were performed on days $1-3$, days $5-8$, and day 21 of each cycle after VV-IL-2 injection, using PCR primers specific for VV-derived IL-2. 
Figure 4. Percentage of tumor biopsies expressing VV-IL-2 (measured as described in the legend to Fig 3) and anti-VV immune status in all six patients. Low Ab titer was defined as an anti-VV Ab titer of $\leq 1 / 80$; high $A b$ titer was defined as an anti-V Ab titer of $>1 / 80$.

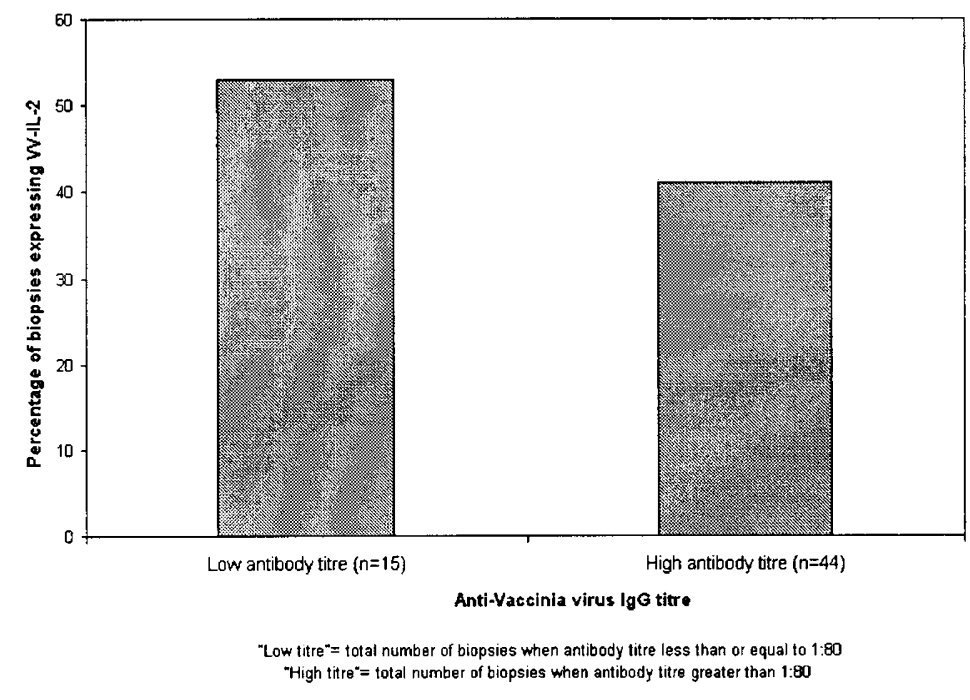

comes the problems of targeting the cytokine to the tumor tissue. Third, we reasoned that the local generation of a specific antitumoral response could potentially induce some level of specific reactivity, breaking tolerance to tumor Ags and inducing reactivity at other sites that are distal to the site of injection. Overall, this approach avoids systemic and intracavity routes, which have potential side effects, and maximizes the chances of generating a high level of gene expression within the tumor itself.

Of critical importance in this study was the determination of the duration and level of gene expression after each VV-IL-2 injection. MM is an ideal tumor to study in this regard, as it is very accessible. Indeed, we limited our pilot study to patients whose tumor had extended between the ribs to form a s.c. deposit, that is, patients in whom we could inject the vector accurately, monitor tumor size directly, and biopsy the injection site with reasonable accuracy. This also minimized the requirement for serial CT scans. PCR techniques provided us with an opportunity to measure the IL- 2 mRNA produced by the VV-IL-2 as distinct from endogenous IL-2. Unfortunately, we cannot be certain that in all cases the tumor biopsies were from the exact site of VV-IL-2 injection, and we cannot estimate the exact distribution or spread of infection around the injection site. It is possible that more cells were actually transduced but were not satisfactorily sampled. However, our decision to focus on s.c. tumor nodules for injection and sampling no doubt markedly increased the likelihood that our sampling procedures were reasonably accurate (in contrast to approaches requiring $\mathrm{CT}$ scan guidance for access to deeper tissues). One of the potential advantages of this vector is that the vector may be rendered replication-competent using the TK region of host tumor cells for replication and may actually spread beyond the original site of injection.

As expected, in patients with very low levels of antiVV immunity, VV-IL-2 mRNA expression was maximal on the first day after injection and then reduced to 
background over $\sim 1-3$ weeks. To our surprise however, a similar pattern was noted in patients whose anti-VV immunity had been boosted. In contrast, when VV-Ag recombinants were used in vaccination studies, systemic immunity limited viral persistence in skin tissues. ${ }^{28}$ This suggests that in our study, the disabling of the VV by the insertion of the IL-2 gene into the TK region altered the growth pattern sufficiently to prevent lysis of the tumor cell, thereby maintaining the VV-IL-2 in intracellular locations where it was not accessible to circulating Abs. Presumably, any anti-VV cytotoxic T lymphocytes were not able to rapidly lyse VV-infected cells within the tumor milieu. These unanticipated observations are encouraging and suggest that VV-IL-2, modified in this way, may represent a good vector for gene transfer. In fact, by disabling the VV by inserting the IL-2 gene into the TK region, the VV will be capable of limited replication in tumor cells, relying on the TK produced endogenously by the tumor cells, whereas it is unlikely to replicate at all in normal cells in which endogenous TK activity is low, adding support to the notion that it may be a useful cancer gene therapy vector.

Although VV-IL-2 mRNA gene expression persisted over relatively prolonged periods, the overall level of expression was modest. Nevertheless, some biological changes were induced within the tumor, manifest as variable increases in T-cell infiltrates at the site of injection. Of course there is no accurate means of determining whether or not this T-cell infiltrate is related to a specific host antitumoral response, due to nonspecific effects of IL-2, due to the presence of the VV alone, or due to some combination of the above. Although the ideal way to follow the immunobiological effects in this system would be to study specific antitumoral reactivities, there is no accurate way to do this in most solid human tumor systems when there are no clearly defined tumor Ags. Cutaneous delayed-type hypersensitivity tests, cytotoxic T-lymphocyte generation, and Western blotting have all been used with variable levels of reproducibility. Using Western blotting and cDNA library screening techniques, we have recently identified some putative MM Ags; in future gene therapy studies in MM, we will attempt to follow host anti-MM reactivity using these techniques. ${ }^{29}$

In this limited study, no tumor regression was noted. Although evaluation of antitumoral effects was not the main aim of this study, the lack of responses in this cohort of patients plus the modest increase in lymphocyte infiltrates in the treated tumors suggests that we have yet to achieve the optimum therapeutic regime using this approach to gene therapy. In subsequent studies, we plan to continue to increase the dose, incorporating multiple genes including IL-2, IL-12, and/or granulocyte-macrophage colony-stimulating factor, cytokines which have proven to be the most powerful inducers of anti-MM responses in our murine model and have the potential to act synergistically.

In conclusion, this VV-cytokine construct, when injected directly into a solid tumor, is associated with prolonged levels of viral-derived cytokine mRNA re- gardless of the presence of a systemic antiviral humoral immune response, supporting the notion that the use of $\mathrm{VV}$ as a cytokine vector has promise as an immunological gene therapy approach in patients with solid malignancy.

\section{ACKNOWLEDGMENTS}

We thank T. Turner for administrative support in the preparation of the protocol and for the typing of this manuscript and Dr. L. Palmer for assistance with graph presentations and statistical analysis. This work was supported in part by funds from the National Health and Medical Research Council of Australia, the Western Australian Institute for Medical Research, the State Government Insurance Commission, the Sir Charles Gairdner Hospital Research Foundation, the James Hardie Industries Medical Research Fellowship, and the Medical Research Fund of Western Australia (MEDWA).

\section{REFERENCES}

1. Rosenberg SA. Cancer vaccines based on the identification of genes encoding cancer regression antigens. Immunol Today. 1997; 18:175-182.

2. Kradin RL, Kurnick JT, Lazarus DS, et al. Tumor-infiltrating lymphocytes and interleukin-2 in treatment of advanced cancer. Lancet. 1989;1:577-580.

3. Straten PT, Becker JC, Seremet T, Brocker EB, Zeuthen J. Clonal $\mathrm{T}$ cell responses in tumor-infiltrating lymphocytes from both regressive and progressive regions of primary human malignant melanoma. J Clin Invest. 1996;98:279284.

4. Davidson JA, Musk AW, Wood Baker R, et al. Intralesional cytokine therapy in cancer: a phase 1 and 2 study of GM-CSF infusion in mesothelioma. J Immunother. 1998; 21:389-398.

5. Sobol RE, Scanlon KJ. Cancer gene therapy clinical trials. Cancer Gene Ther. 1995;2:5-6.

6. Tursz T, Le Cesne A, Baldeyrou P, et al. Phase 1 study of a recombinant adenovirus-mediated gene transfer in lung cancer patients. J Natl Cancer Inst. 1996;88:1857-1863.

7. Sterman DH, Treat J, Litzky LA, et al. Adenovirusmediated herpes simplex virus thymidine kinase/ganciclovir gene therapy in patients with localized malignancy: results of a phase I clinical trial in malignant mesothelioma. Hum Gene Ther. 1998;9:1083-1092.

8. Ramshaw IA, Andrew ME, Phillips SM, Boyle DB, Coupar BEH. Recovery of immunodeficient mice from a vaccinia virus/IL-2 recombinant infection. Nature. 1987; 329:545-546.

9. Ruby J, Brinkman C, Jones S, Ramshaw I. Response of monkeys to vaccination with recombinant vaccinia virus which coexpress HIV gp160 and human interleukin-2. Immunol Cell Biol. 1990;68:113-117.

10. Cooney EL, Collier AC, Greenberg PD, et al. Safety of and immunological response to a recombinant vaccinia virus vaccine expressing HIV envelope glycoprotein. Lancet. 1992;337:567-572.

11. Acres B, Dolt K, Stefani L, Kierry MP. Directed cytokine expression in tumor cells in vivo using recombinant vaccinia virus. Ther Immunol. 1994;1:17-23.

12. Robinson BWS, Garlepp MJ, Scott B. Mesothelioma. In: Crystal RG, West JB, eds. The Lung: Scientific Foundations. 2nd ed. New York: Raven Press; 1995:2599-2610. 
13. Armstrong BK, Musk AW, Baker JE, et al. Epidemiology of malignant mesothelioma in Western Australia. Med J Aust. 1984;141:86-88.

14. Upham J, Musk AW, Robinson BWS. Mesothelioma: new therapeutic approaches. In: G Peters, ed. Sourcebook on Asbestos Diseases. Vol 8. New York: Garland Publishing; 1993:191-200.

15. Robinson BWS, Davidson JA, Garlepp MJ. The immunology and immunopathology of malignant mesothelioma. In: Kradin RL, Robinson BWS, eds. Immunopathology of Lung Disease. Newton, Mass: Butterworth Heinemann; 1996:491-513.

16. Davis MR, Manning LS, Whitaker D, Robinson BWS. Establishment of a murine model of malignant mesothelioma. Int J Cancer. 1992 52:881-886.

17. Leigh R, Webster I. Lymphocytic infiltration of pleural mesothelioma and its significance for survival. $S$ Afr Med J. 1982;61:1007-1009.

18. Christmas TI, Manning LS, Garlepp MJ, Musk AW, Robinson BWS. Effect of interferon $\alpha-2 \mathrm{a}$ on malignant mesothelioma. J Interferon Res. 1993;13:9-12.

19. Leong CC, Marley JV, Loh S, Robinson BWS, Garlepp MJ. The induction of immune responses to murine malignant mesothelioma by IL-2 gene transfer. Immunol Cell Biol. 1997; 75:356-359.

20. Fakharai H, Shawler D, Gjerset R, et al. Cytokine gene therapy with interleukin 2-transduced fibroblasts: effects of IL-2 dose on anti-tumor immunity. Hum Gene Ther. 1995;6:591-601.

21. Rosenberg SA, Packard BS, Aebersold PM, et al. Use of tumor-infiltrating lymphocytes and interleukin-2 in the immunotherapy of patients with metastatic melanoma. N Engl J Med. 1988;319:1676-1680.

22. Rosenberg SA, Lotze MT, Muul LM, et al. A progress report on the treatment of 157 patients with advanced cancer using lymphokine-activated killer cells and interleukin-2 or high-dose interleukin-2 alone. $N$ Engl $J$ Med. 1987;316:889-897.

23. West WH, Tauer KW, Yannelli JR, et al. Constant infusion recombinant interleukin-2 in adoptive immunotherapy of advanced cancer. N Engl J Med. 1987;316:898-905.

24. Sosman JA, Kohler PC, Hank J, et al. Repetitive weekly cycles of recombinant human interleukin-2: responses of renal carcinoma with acceptable toxicity. J Natl Cancer Inst. 1988;80:60-63.

25. Burdick KH, Haw WA. Vitiligo in a case of vaccinia virus-treated melanoma. Cancer. 1964;17:708-712.

26. Lane-Brown MM, Burnett JB. Non-specific immunotherapy of cutaneous melanoma using vaccinia.. Reprinted from Multiple Primary Malignant Tumors. In: Severi L, ed. Fifth Perugia Quadrennial International Conference on Cancer 1973. Perugia Monteluce, Italy: Division of Cancer Research; 1975.

27. Roenigk HH Jr, Deodhar S, St Jacques R, Burdick K. Immunotherapy of malignant melanoma with vaccinia virus. Arch Dermatol. 1974;109:668-673.

28. Everall JD, O'Doherty CJ, Wand J, Dowd PM. Treatment of primary melanoma by intralesional vaccinia before excision. Lancet. 1975;7935:583-586.

29. Robinson C, Robinson BWS, Lake RA. Sera from patients with malignant mesothelioma contain autoantibodies. Lung Cancer. 1998;20:175-184. 